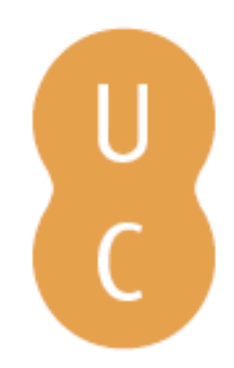

\title{
nombalina
}

\section{Doença alérgica}
Autor(es):
Pinheiro, José António
Publicado por: Imprensa da Universidade de Coimbra
URL persistente:
URI:http://hdl.handle.net/10316.2/43121
DOI:
DOI:https://doi.org/10.14195/978-989-26-1300-0_20

Accessed : $\quad$ 26-Apr-2023 13:03:05

A navegação consulta e descarregamento dos títulos inseridos nas Bibliotecas Digitais UC Digitalis, UC Pombalina e UC Impactum, pressupõem a aceitação plena e sem reservas dos Termos e Condições de Uso destas Bibliotecas Digitais, disponíveis em https://digitalis.uc.pt/pt-pt/termos.

Conforme exposto nos referidos Termos e Condições de Uso, o descarregamento de títulos de acesso restrito requer uma licença válida de autorização devendo o utilizador aceder ao(s) documento(s) a partir de um endereço de IP da instituição detentora da supramencionada licença.

Ao utilizador é apenas permitido o descarregamento para uso pessoal, pelo que o emprego do(s) título(s) descarregado(s) para outro fim, designadamente comercial, carece de autorização do respetivo autor ou editor da obra.

Na medida em que todas as obras da UC Digitalis se encontram protegidas pelo Código do Direito de Autor e Direitos Conexos e demais legislação aplicável, toda a cópia, parcial ou total, deste documento, nos casos em que é legalmente admitida, deverá conter ou fazer-se acompanhar por este aviso.

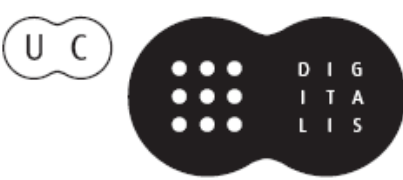


Capítulo 20.

Doença alérgica
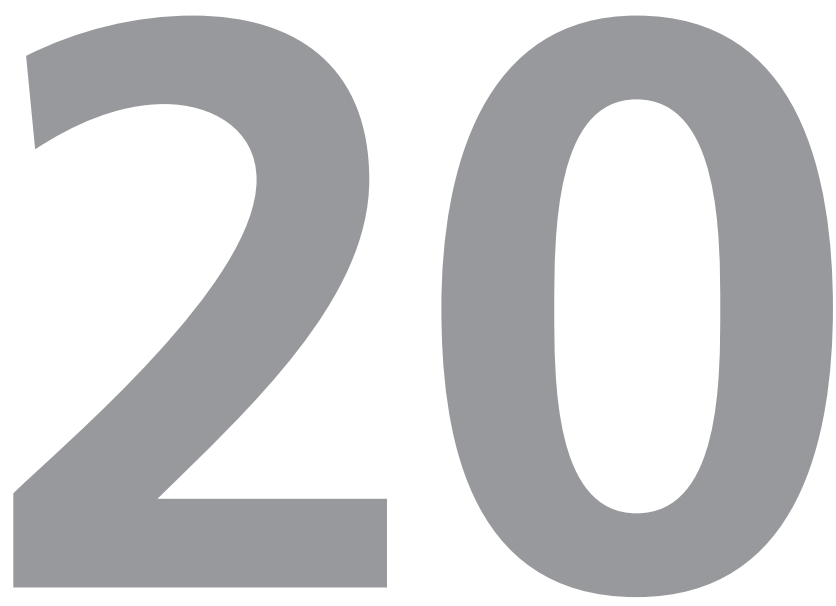

José António Pinheiro 


\subsection{CONTEXTO}

\section{Definição de conceitos}

\section{Hipersensibilidade:}

Manifestações clínicas reprodutíveis, que surgem com a exposição a um estímulo, em doses toleradas por pessoas normais.

\section{Alergia:}

Reação de hipersensibilidade mediada por um mecanismo imunológico [imunoglobulina $\mathrm{E}$ (IgE) ou não lgE] que ocorre quando um indivíduo geneticamente suscetível reage anormalmente a um antigénio.

\section{Atopia}

Predisposição geneticamente determinada para produzir IgE em resposta a alergénios. Hipótese higiénica: é uma teoria ambiental para explicar o aumento da prevalência das doenças alérgicas nos países mais desenvolvidos e nos ambientes urbanos. Sugere que uma exposição reduzida a micro-organismos (ou endotoxinas) nos primeiros meses e anos de vida pode contribuir para o aumento das doenças atópicas. O ambiente urbano e o estilo de vida moderno, ocidentalizado, em que as crianças vivem em pequenos agregados familiares, com menor exposição a infeções, mas mais medicadas com antipiréticos (paracetamol) e antibióticos, seriam fatores favorecedores de doença alérgica. Paralelamente, haveria uma redução na atividade das células $T$ reguladoras.

\section{Marcha alérgica:}

As crianças alérgicas desenvolvem doenças alérgicas distintas em idades diferentes: eczema atópico e alergia alimentar nos primeiros anos de vida, precedem o aparecimento de rino-conjuntivite e asma na idade pré-escolar e escolar.

\section{Doença alérgica:}

Manifestações da alergia nos vários órgãos-alvo: brônquios (asma brônquica), nariz (rinite alérgica), olhos (conjuntivite alérgica) ou pele (eczema atópico, urticária, angioedema). Há manifestações alérgicas simultâneas em vários órgãos (anafilaxia, alergia alimentar, rino-conjuntivite, rino-asma).

\section{Phadiatop:}

Teste laboratorial com conjunto de IgE específicas usado para rastrear sensibilização a inalantes.

\section{Food-mix:}

Teste laboratorial com conjunto de IgE específicas usado para rastrear sensibilização a alimentos.

\section{Prick test:}

Testes cutâneos de alergia através de picada com extratos alergénicos.

\section{Prick-to-Prick:}

Testes cutâneos de alergia através de picada com o alergénio em natureza.

\section{Prevenção das doenças alérgicas}

Várias intervenções têm sido propostas para evitar o aparecimento da doença alérgica ou para travar a marcha alérgica. Muitas sem sucesso, algumas com evidência: o aleitamento materno exclusivo até aos quatro meses, leites hidrolisados 
de proteínas, probióticos e prebióticos, ácidos gordos ómega-3, vitamina $D$ e antioxidantes. A imunoterapia específica (SIT) para um determinado alergénio é apontada por alguns autores como o único meio de travar a marcha alérgica, evitando novas sensibilizações.

\subsection{DESCRIÇÃO DO TEMA}

As principais doenças alérgicas em Pediatria são: asma; rinite alérgica; anafilaxia; alergia alimentar; alergia a fármacos; alergia a insetos; dermatite atópica; urticária e angioedema.

\subsubsection{Asma}

Habitualmente começa antes dos dois anos de idade, com uma bronquiolite viral. No entanto, ao contrário desta situação de causa infeciosa, a criança asmática repete o mesmo quadro de dispneia expiratória quando inicia outro catarro respiratório. Não se deve usar o termo «bronquiolites de repetição» pois a bronquiolite raramente se repete. Passará a designar-se Asma Induzida por Vírus (AIV) e, a partir do segundo episódio, deverão ser usados nessas agudizações os broncodilatadores inalados e mesmo os corticoides orais se necessário. Recordamos que estes medicamentos não fazem parte da terapêutica da bronquiolite, são fármacos usados nas crises de asma. Este fenótipo de AIV é o mais comum na criança, mesmo na asma alérgica. Cerca de 25\% das crianças apresenta sibilância recorrente em idade pré-escolar. Raramente a doença surge mais tarde, com predomínio de outros fenótipos
- Asma Induzida por Esforço (AIE) ou Asma Induzida por Alergénios (AIA). Com o crescimento, as formas mistas são a regra.

Podemos então considerar o diagnóstico clínico de asma em Pediatria perante uma criança que teve pelo menos três episódios de dispneia expiratória, ou pieira, ou tosse equivalente asmática de predomínio noturno. Resposta positiva aos broncodilatadores inalados é uma boa ajuda ao diagnóstico. A exclusão de outras patologias com clínica semelhante é obrigatória, mas geralmente não são necessários exames complementares. Recorde-se que o diagnóstico é clínico, o estudo alergológico serve apenas para detetar a atopia. No lactente e no pré-escolar o diagnóstico diferencial faz-se sobretudo com a broncopneumonia viral ou por bactérias atípicas e com o refluxo gastro-esofágico. Raramente a fibrose quística se apresenta como uma asma sem que haja outras manifestações da doença.

Na asma há hiperreatividade brônquica e inflamação crónica, mas geralmente o doente não apresenta sintomas. Estes surgem nas crises ou exacerbações - tosse, pieira, dispneia expiratória, aperto torácico. Os vírus respiratórios são os principais desencadeantes de crise em todas as idades. As bactérias atípicas (Mycoplasma pneumoniae e Chlamydia) raramente são responsáveis. Outros desencadeantes são os alergénios a que o doente está sensibilizado (ácaros, pólens, animais domésticos) e os irritantes inespecíficos (sobretudo o fumo de tabaco). Fatores emocionais desencadeiam crise em alguns doentes que apresentam tosse, pieira ou mesmo dispneia com o riso, o choro ou apenas stresse emocional (não confundir com a dispneia ansiosa e hiperventilação, que não cursam com broncospasmo). Quando 
algum destes fatores predomina, permite definir um fenótipo clínico desse doente.

Na idade escolar e no adolescente é muito frequente o broncospasmo ou AIE. Em regra, todo o doente asmático, quando inquirido, reconhece sintomas relacionados com o exercício físico - dor ou aperto retro-esternal, dispneia, tosse ou pieira. A atividade física mais asmogénica consiste na corrida ao ar livre, frio e seco, sem aquecimento prévio e nos desportos de inverno. Os sintomas descritos obrigam o doente a interromper o exercício ou a abrandar o ritmo. Raramente se recorre à prova de esforço em laboratório para confirmar o diagnóstico - a clínica e a prova terapêutica são suficientes. O professor de Educação Física, treinador ou instrutor estará informado e o jovem sabe como e quando se automedicar - em regra com um broncodilatador inalado, quinze minutos antes do esforço. O inalador estará sempre disponível. Quando o broncodilatador pré-esforço não é suficiente, recorre-se a medicação diária preventiva com corticoide inalado ou antagonista dos leucotrienos.

O tratamento da crise de asma é iniciado precocemente, logo que surge o primeiro sintoma - um aperto torácico, como vimos, ou apenas tosse, irritativa, com agravamento noturno. A dispneia expiratória pode traduzir-se apenas por um prolongamento do tempo expiratório, sobretudo nos primeiros anos de idade. A pieira e os correspondentes sibilos predominam na expiração. A ausência de sibilos e o apagamento do murmúrio vesicular são sinais de crise grave. Num Serviço de Urgência (SU) a saturação periférica de oxigénio (SpO2) é sempre avaliada, sendo decisiva para a administração de oxigénio. Em todas as circunstâncias, o broncodilatador inalado é o primeiro medicamento a usar na crise - salbutamol ou terbutalina, conforme o dispositivo que o doente é portador e com o qual está familiarizado. Mesmo no SU é aconselhável o doente usar o seu broncodilatador com o seu dispositivo, mas em doses superiores. Quando a crise não cede a doses generosas de broncodilatador, com dispositivo e técnica adequados, teremos que combater o edema e a inflamação que se associam ao broncospasmo. Associa-se um corticoide sistémico por via oral - prednisolona, metilprednisolona, dexametasona ou deflazacort. A dose de referência para a prednisolona é de 1 a $2 \mathrm{mg} / \mathrm{kg} / \mathrm{dia}$ (máximo $50 \mathrm{mg}$ ) em ciclo curto de três a cinco dias, sem necessidade de desmame. Muito raramente se recorre à via intravenosa, que não tem vantagens sobre a via oral, exceto em casos de intolerância ou recusa. Durante o ciclo de corticoide oral, os broncodilatadores são mantidos na dose habitual. Os broncodilatadores inalados mais usados são os agonistas dos recetores beta $\left(\beta_{2}\right)$ de curta duração de ação (SABA) - salbutamol (pressurizado ou em pó) e a terbutalina (apenas disponível em pó). O formoterol, agonista beta de longa duração (LABA) pelo seu início de ação igualmente rápido, será uma alternativa nos doentes que já o usam em terapêutica de fundo, preventiva. O brometo de ipratrópio, anticolinérgico com reduzida ação broncodilatadora, aumenta o efeito dos agonistas beta, estando indicado em segunda linha, sempre em associação. A via inalatória é a via de eleição para os broncodilatadores, pois permite um tratamento tópico, com menos doses, mais rápido e eficaz e com menos efeitos secundários, podendo administrar-se doses repetidas em curtos intervalos de tempo. Recorre-se a câmaras expansoras para os inaladores pressurizados sempre que o 
doente não domina a técnica de coordenação mão-pulmão, como é o caso das crianças.

A terapêutica de controlo da asma, preventiva ou de fundo, baseia-se no combate aos fatores desencadeantes das crises. A dessensibilização alergénica (imunoterapia específica) é usada nalguns casos de asma ou outras doenças alérgicas mediadas por lgE. É dirigida à alergia em si, não à doença asmática, que nem sempre é alérgica. Muitos doentes têm a asma controlada sem necessidade de medicamentos preventivos - raras e leves exacerbações, sem recorrer a SU, sono e atividade sem restrições, incluindo exercício físico, as provas funcionais respiratórias (espirometria) não mostram um padrão obstrutivo; usam apenas um broncodilatador em S.O.S. e passam semanas ou meses sem deles necessitar. Nos casos em que a asma não está controlada ou está parcialmente controlada teremos que recorrer a medicamentos preventivos, de forma contínua, diária. Em primeira linha usam-se corticoides inalados (budesonida, fluticasona). Nas crianças em idade pré-escolar com AIV o montelucaste é uma alternativa ao corticoide inalado, podendo usar-se em monoterapia ou em associação. Em todos os doentes, o controlo da asma é baseado em degraus terapêuticos, procurando a medicação mínima que controle a doença, satisfazendo os critérios de asma controlada descritos acima. Até atingir esse controlo, sobem-se degraus terapêuticos, aumentando as doses de corticoide inalado, associando antagonistas dos recetores dos leucotrienos (montelucaste é o mais usado em Pediatria) ou associando agonistas dos recetores $\beta$ com longa duração de ação (formoterol ou salmeterol). Nestes casos a medicação de controlo será dupla ou tripla, havendo dispositivos que contêm dois fármacos no mesmo inalador. Há casos excecionais de asma grave, de difícil controlo em que, mesmo depois de otimizada toda a terapêutica, o seu cumprimento por parte do doente, a técnica inalatória e a evicção dos fatores agravantes, não se consegue controlar a doença. Ponderamos então associar um anticorpo monoclonal anti-lgE (omalizumab) - esta terapêutica é de uso exclusivo em meio hospitalar, muito dispendiosa, requer via injetável (subcutânea) com doses periódicas (quinzenais ou mensais) e por tempo prolongado (anos). Nenhum medicamento usado na asma é isento de efeitos secundários eventuais. Porém, usando as doses e as associações preconizadas e respeitando as normas para cada grupo etário, a terapêutica é segura, mesmo usada a longo prazo, sem consequências futuras.

A terapêutica inalatória é, como dissemos, de eleição, tanto para o tratamento das crises como de manutenção. Exige domínio da técnica por parte do doente e da família, sendo imprescindível que os profissionais de saúde façam o ensino e verificação de erros, bastante frequentes, aliás. Não se pode prescrever um medicamento inalado sem exemplificar e confirmar que o doente aprendeu e colabora, testando a sua competência e adaptando o dispositivo a cada grupo etário e individualmente. Na idade pré-escolar usam-se os inaladores pressurizados (metered-dose inhaler - pMDI) com câmara expansora. Esta tem uma máscara facial acoplada que facilita a inalação nos primeiros anos de vida. Pelos três ou quatro anos a criança já consegue inalar pelo bocal da câmara. Os pMDI contêm uma mistura do fármaco com gás pressurizado, libertando-o sob a forma de spray. Só no adolescente treinado poderão ser usados diretamente, sem câmara. A partir dos 
cinco ou seis anos, a maioria das crianças aprende a inalar medicamentos em forma de pó seco (dry Powder Inhaler-DPI) - o fármaco encontra-se em contentores de pó muito fino que é inalado à custa de um dispositivo com bocal, exigindo um fluxo inspiratório suficiente para o transportar até à árvore brônquica. São muito práticos, portáteis e os mais usados desde a idade escolar à adolescência, incluindo adultos. Uma referência final aos nebulizadores, que só são usados em SU, para administrar grandes doses de broncodilatadores em casos graves ou em doentes incapazes de usar inaladores.

\subsubsection{Rinite alérgica}

A rinite é a doença alérgica mais prevalente. Coexistindo quase sempre com a asma ( $80 \%$ dos doentes asmáticos têm rinite como co-morbilidade) pode existir de forma isolada, constituindo por si um fator de risco para o desenvolvimento de asma (cerca de 30\% dos doentes com rinite têm ou virão a ter asma). Uma rinite não tratada ou mal controlada pode ser responsável por uma asma mal controlada. Afeta também a qualidade de vida e a escolaridade.

Os sintomas são característicos - prurido, obstrução ou congestão, rinorreia e espirros. O prurido é referido ao nariz, olhos, faringe, palato mole e por vezes aos ouvidos. A obstrução nasal compromete o fluxo, obrigando a respiração bucal, sobretudo noturna, geralmente acompanhada de roncopatia ou mesmo apneia do sono. A rinorreia é serosa ou seromucosa, anterior e posterior (provocando um fungar repetido ou uma tosse produtiva crónica). As salvas de espirros ou crises esternutatórias são típicas, podendo chegar a cinco ou dez espirros, intervalados de alguns segundos.

O doente coça o nariz com a palma da mão, num movimento ascendente descrito como saudação alérgica, o que causa uma típica prega transversal na pirâmide nasal e um nariz arrebitado, com bordos grossos nas abas nasais. Quando coça sem mão, faz esgares ou caretas. O prurido do palato e da faringe provoca sons guturais e pigarro. À nasoscopia vê-se hipertrofia dos cornetos inferiores, que estão inflamados, azulados ou pálidos, por vezes recobertos por muco filante. Junto às pálpebras inferiores há zonas violáceas ou acastanhadas, conferindo um aspeto olheirento, devido à congestão venosa da rinossinusite que acompanha a rinite, e que é a responsável pela dor e tensão frontal e malar. As pálpebras inferiores têm uma dupla prega (pregas de Dennie-Morgan) que confere uma facies atópica caraterística.

$\mathrm{Na}$ idade pré-escolar a rinite associa-se geralmente a otite seromucosa.

A rinoconjuntivite alérgica ( $R C A$ ) pode ser sazonal (polínica) ou perene, dependendo da exposição ao alergénio. Nas alergias indoor (ácaros, animais domésticos) havendo um contacto diário, peranual, com os alergénios, o componente obstrutivo costuma ser predominante. Nas alergias outdoor (pólens) o contacto é sazonal e tornam-se mais evidentes a rinorreia, espirros e prurido. Com base na duração de sintomas, classifica-se como persistente ou intermitente (mais/menos de quatro dias por semana ou mais/menos de quatro semanas por ano); ou episódica (i.e. contacto esporádico com um alergénio).

Os anti-histamínicos ( $\mathrm{AH}$ ) melhoram sobretudo o prurido, tendo algum efeito sobre a rinorreia e os espirros, mas não sobre a obstrução. 
Usam-se sobretudo por via oral e apenas estão indicados os AH não-sedativos, de segunda geração (loratadina e desloratadina; cetirizina e levocetirizina; ebastina; rupatadina). São úteis nas agudizações, de acordo com a exacerbação dos sintomas, mas também em períodos prolongados (meses). Melhoram também os sintomas oculares. A azelastina é um AH tópico, nasal ou ocular atuando por ação local nos mesmos sintomas que os $\mathrm{AH}$ orais.

Os corticoides tópicos (budesonida, fluticasona, mometasona) atuam sobre todos os componentes da rinite, sendo imprescindíveis quando há grande hipertrofia dos cornetos, obstrução e redução dos fluxos nasais. Devem usar-se por períodos prolongados (várias semanas) sendo seguros em Pediatria. Porém a técnica de administração e a aceitação em idade pré-escolar limitam o seu uso nos primeiros anos de vida.

\subsubsection{Anafilaxia}

É uma reação alérgica sistémica grave, de hipersensibilidade imediata, que ocorre minutos ou poucas horas após exposição a um alergénio, tem início súbito e sintomas progressivos, podendo chegar ao choque e, potencialmente, ser fatal. Afeta vários órgãos em simultâneo. Na pele e mucosas cursa com prurido, urticária e angioedema labial e palpebral, raramente da língua e da úvula. A hipotensão, hipotonia e a síncope são frequentes, devendo ser feito o diagnóstico diferencial com síncope vasovagal. Podem associar-se sinais respiratórios (pieira, dispneia, estridor) ou digestivos (vómitos, cólicas e diarreia). Nos primeiros anos de vida deve valorizar-se a má impressão clínica criança hipotónica e hiporreativa, pálida, com olhar vago. O diagnóstico é clínico e o contacto recente com um alergénio conhecido para aquele doente facilita a decisão. A terapêutica é de emergência, mesmo em caso de dúvida - administra-se adrenalina por via intramuscular na face externa da coxa, na dose de $\mathbf{0 , 0 1} \mathbf{~ m g} / \mathbf{k g}$ (a dose máxima pediátrica é de 0,3 mg). A adrenalina, também chamada epinefrina, tem uma concentração de $1 \mathrm{mg} / \mathrm{ml}$ (milesimal) pelo que usamos na prática a dose de $0,01 \mathrm{ml} / \mathrm{kg}$ (ou seja 0,1 $\mathrm{ml}$ por cada 10 $\mathrm{kg}$ de peso). Esta dose é repetida passados dez minutos na ausência de resposta. Em caso de choque ou paragem cárdio-respiratória procede-se às medidas de reanimação. É necessário canalizar uma veia e, em caso de broncospasmo, administrar broncodilatadores por via inalatória. Os corticoides sistémicos e os anti-histamínicos só são usados depois de tomadas estas medidas, já que têm um início tardio de ação.

Os principais alergénios causadores de anafilaxia são os alimentos - proteínas do leite de vaca, frutos de casca rija, frutos frescos, amendoim, peixe, marisco e ovo. A anafilaxia a medicamentos é rara e às vacinas é excecional.

A alergia ao látex pode causar anafilaxia, sobretudo no bloco operatório, quando se desconhece que o doente é alérgico. É mais frequente em doentes submetidos a várias intervenções cirúrgicas e nos doentes com espinha bífida (algaliações repetidas). Obriga à evicção de qualquer contacto com objetos de borracha, à preparação prévia de uma sala de operações "latex-free" e à exclusão de alergia cruzada a alguns alimentos castanha, kiwi, banana, pêssego, abacate, entre outros - conhecida como síndrome látex-frutos.

Uma forma rara e poucas vezes reconhecida de anafilaxia é a Food Dependent Exercise Induced 
Anaphylaxis (FDEIA). Como o nome indica trata-se de uma anafilaxia que surge durante o esforço físico mas que está dependente de um alergénio alimentar previamente ingerido, a que o doente em geral está sensibilizado. A anafilaxia só ocorre na sequência ingestão-exercício, pelo que a prevenção passa pelo afastamento temporal dos dois fatores desencadeantes (não praticar esforços nas duas ou três horas que se seguem à ingestão do alimento identificado, em regra o trigo e outros cereais, leguminosas ou leite).

Todo o doente com risco ou com passado de anafilaxia deve fazer-se acompanhar de auto-injetor de adrenalina, sendo a família e os professores informados das indicações e técnica de administração. Na escola ou infantário haverá um auto-injetor acessível.

\subsubsection{Alergia alimentar}

Trata-se de uma reação imunológica, em regra mediada por IgE, a uma proteína alimentar específica. Leite de vaca, ovo, peixe, frutos frescos, frutos de casca rija, mariscos, amendoim são os alimentos mais vezes implicados.

\section{A alergia às proteínas do leite de vaca}

(APLV) representa cerca de metade das alergias alimentares em idade pediátrica. É uma alergia transitória na grande maioria dos casos, visto que 80 \% das crianças adquire tolerância nos primeiros três anos de idade. Só em $20 \%$ dos casos a alergia persiste. A apresentação clínica habitual é uma urticária que surge nos primeiros meses de vida, após a ingestão de leite de fórmula ou papa láctea num lactente exclusivamente alimentado com leite materno. Por vezes há angioedema ou vómitos associados, raramente anafilaxia. Nos antecedentes pessoais é usual relatar-se um contacto precoce com PLV nos primeiros dias de vida, quase sempre um "biberão de leite adaptado na Maternidade" responsável pela sensibilização (priming). O mecanismo imunológico nestes casos é mediado por IgE, como se pode evidenciar por testes epicutâneos (Prick test ou Prick-to-Prick) ou pela elevação das IgE séricas específicas das proteínas do leite de vaca (caseína, beta-lactoglobulina, alfa-lactalbumina, as principais). Quando a APLV não é mediada por lgE as manifestações clínicas são mais inespecíficas - má progressão ponderal, diarreia, hematoquésia (por retocolite), irritabilidade e cólicas abdominais. Em caso de dúvida, a prova de provocação oral (PPO) após um período de exclusão de PLV na dieta será sempre o meio gold standard para o diagnóstico. O tratamento da APLV consiste na substituição do aleitamento por fórmulas com proteínas extensamente hidrolisadas (eHF); excecionalmente recorre-se a fórmulas de aminoácidos. A APLV pode ainda surgir num lactente amamentado, sendo as PLV veiculadas pelo leite materno (LM). É uma situação rara, estando indicada a exclusão de produtos lácteos da dieta materna, mantendo o LM. A aquisição de tolerância é testada sequencialmente pela monitorização das IgE séricas específicas, pelos testes cutâneos e finalmente por uma PPO negativa. Recordamos que qualquer doente com APLV não pode ingerir nenhum alimento que contenha proteína de LV ou de outros leites não testados (i.e. de cabra). As fórmulas à base de proteína de soja são uma alternativa nos casos em que há uma alergia persistente mediada por lgE, mas deverá sempre ser feita uma prova de tolerância prévia em meio hospitalar. Como é evidente, um doente com APLV pode ingerir 
alimentos contendo lactose (açúcar do leite). A leitura sistemática dos rótulos dos alimentos é obrigatória, para evitar acidentes com alergénios ocultos. A confeção em casa, nas creches e escolas, nas festas de aniversário e convívios, ou em qualquer estabelecimento de restauração, tem que ser investigada para cada refeição.

A alergia ao ovo é a segunda mais frequente em Pediatria, depois da APLV, representando cerca de $25 \%$ das alergias alimentares da criança, sendo também transitória na maioria dos casos. A ovoalbumina e ovomucoide da clara são as principais proteínas responsáveis. A gema é menos alergénica, mas deve ser também testada. Os testes cutâneos Prick-to-Prick são o melhor método de diagnóstico, pois permitem testar separadamente a reatividade a ovo cru e cozido, à clara e à gema. A alergia mais persistente e mais perigosa é à clara crua. Em casos de dúvidas ou para confirmar a aquisição de tolerância a qualquer dos componentes, a PPO está indicada, sempre feita em meio hospitalar. As crianças com alergia confirmada ao ovo não devem ser vacinadas contra a gripe nem febre amarela, mas devem receber normalmente a vacina do sarampo, constituinte da VASPR. Só em casos com história prévia de uma reação grave ao ovo, se justifica a administração da vacina em meio hospitalar. Tal como em outras alergias alimentares, o doente e a família devem ser educados para os riscos de acidente com alergénios ocultos, questionando a composição de todos os alimentos suspeitos.

Ao contrário da alergia ao leite e ao ovo acima descritas, geralmente transitórias, as alergias a peixe e mariscos, frutos de casca rija, amendoim, frutos frescos e cereais costumam persistir para toda a vida.
A anafilaxia é um risco sempre presente devido à ingestão acidental do alimento em causa, pelo que todos estes doentes devem receber instruções para tratamento de emergência, fazendo-se acompanhar de um auto-injetor de adrenalina (Anapen $囚)$. Até à adolescência serão os familiares ou cuidadores a administrar a adrenalina por via intramuscular.

\subsubsection{Alergia a fármacos}

Em Pediatria, a suspeita de alergia a antibióticos $\beta$ lactâmicos é frequentemente evocada, mas apenas se confirma em menos de $10 \%$ dos casos. Muitas crianças são rotuladas de "alergia à penicilina" ou "alergia à amoxicilina" porque desenvolveram um exantema durante uma doença infeciosa, geralmente viral, para a qual foram, erradamente, medicadas com um antibiótico. Em 90\% dos casos trata-se de facto de exantemas virais, específicos ou inespecíficos, por vezes resultantes de uma interação vírus-fármaco. Mesmo que a história evoque esse diagnóstico, há que esclarecer essa suspeita de alergia. $\mathrm{Na}$ grande maioria dos casos, basta uma PPO com o fármaco, realizada com a criança saudável e sempre iniciada em meio hospitalar (Hospital de Dia). Sob vigilância clínica são administradas doses orais fracionadas do fármaco suspeito, tendo disponível adrenalina para uma anafilaxia imprevisível. Se não houver qualquer sinal ou sintoma nas primeiras horas, a criança poderá continuar a PPO e a vigilância fora do hospital, alertando a família para os sinais de alarme e a atitude a tomar. Não havendo reação ao fim do tempo e das doses programadas, exclui-se alergia. Em cerca de $10 \%$ dos casos surgem sintomas 
ligeiros, geralmente exantemas maculopapulares não acompanhados de outros sinais de gravidade - nestes doentes confirma-se então a alergia e recomendam-se fármacos alternativos (no caso de alergia à amoxicilina, sugere-se o cefuroxime axetil). Somente nos casos com história de anafilaxia ou de reação imediata está indicado o doseamento de IgE específica ou testes cutâneos antes de avançar para uma PPO. Uma forma rara de hipersensibilidade a fármacos, em geral a amoxicilina e cefaclor, é a Doença do SoroLike (DSL). Mediada por imunocomplexos, o seu diagnóstico é meramente clínico, baseado num exantema que surge sete a quinze dias após o início da medicação, com características de eritema multiforme ou de vasculite e sempre acompanhado de artrite ou artralgias, de predomínio nos membros inferiores, causando impotência funcional. Não é necessário (nem ético) submeter o doente a uma PPO nestes casos de DSL. De referir que uma PPO estará também contra-indicada em casos de anafilaxia ou toxidermia grave (Necrólise Epidérmica Tóxica, Síndrome de Stevens-Johnson).

\subsubsection{Alergia a insetos}

\section{A Hipersensibilidade a picada de insetos (prurigo estrófulo) é a dermatite} pediátrica mais comum. Consiste em reações cutâneas localizadas à picada de pulgas, melgas e mosquitos, sobretudo nos meses quentes e predominando nas pernas, braços e cintura. A lesão inicial é uma urticária papular de um ou dois $\mathrm{cm}$ rosada e muito pruriginosa, que evolui para uma vesícula; esta rompe, forma uma crosta, que ao cair deixa uma mácula acrómica como lesão residual. A criança ou adolescente surge com lesões nas várias fases em regra com história de meses ou anos de recorrência. A face é quase sempre poupada, tal como o couro cabeludo, nunca há lesões nas palmas, plantas ou mucosas - o que é uma boa ajuda no diagnóstico diferencial. Não são lesões graves, mas o prurido é muito incómodo e difícil de combater, as lesões são inestéticas, de difícil prevenção, o tratamento pouco eficaz. Aconselha-se evitar a exposição aos insetos (desinfestação dos animais, inseticidas ou mosquiteiros nos dormitórios, cobrir as partes do corpo expostas, repelentes pontualmente). Nas lesões com grande componente inflamatório, aplicar gelo numa fase inicial e um creme de corticoide, que será associado a um antibiótico tópico em caso de impetiginização. Os anti-histamínicos tópicos não estão indicados e os orais são pouco eficazes. Cortar as unhas é recomendável. A tolerância à picada dos insetos pode demorar vários anos a adquirir-se.

\section{A alergia à picada de himenópteros} (abelhas e vespas) é rara em Pediatria. O habitual é uma pápula local dolorosa que deve ser apenas tratada com a aplicação de gelo. Nos casos de verdadeira alergia, o doente apresenta sinais loco-regionais e/ou sintomas e sinais de anafilaxia - hipotensão, bradicardia, sinais neurológicos, respiratórios ou digestivos, angioedema. Está indicado o recurso imediato a adrenalina intramuscular e a partir do primeiro episódio deve ser portador de auto-injetor de adrenalina (Anapen $®$ ). Será também orientado para consulta diferenciada onde estará indicada terapêutica de dessensibilização a veneno de himenópteros. 


\section{Leitura complementar}

GINA - Global Initiative for Asthma. Www.ginasthma.org.

ARIA - Allergic Rhinitis and its Impact on Asthma. WWW. whiar.org.

PRACTALL - Practical Allergy - consensus report. Allergy 2008; 63:5-34

ICON - International consensus on pediatric asthma. Allergy 2012; 67: 976-997.

Norma DGS nº 016 de 27/09/2011, atualizada a 14/6/2012 www.dgs.pt.

Manual para a abordagem da sibilância em idade pediátrica www.dgs.pt. 